\title{
EL ANILLO VERDE DE VITORIA-GASTEIZ. UNA PRÁCTICA EXITOSA PARA UN PLANEAMIENTO URBANO SOSTENIBLE
}

\author{
Itziar Aguado \\ Departamento de Geografía, Prehistoria y Arqueología. Universidad del País Vasco (UPV/EHU) \\ itziar.aguado@ehu.es \\ José M. Barrutia \\ Departamento de Economía Financiera II. Universidad del País Vasco (UPVIEHU) \\ josemaria.barrutia@ehu.es \\ Carmen Echebarria \\ Departamento de Economía Aplicada V. Universidad del País Vasco (UPV/EHU) \\ carmen.etxebarria@ehu.es
}

El concepto de sostenibilidad se ha convertido en uno de los paradigmas dominantes en la planificación urbana de los últimos tiempos, al menos en el ámbito de la teoría académica, donde los discursos e ideologías relativas a la sostenibilidad han obtenido una amplia difusión. Sin embargo, nos encontramos que en la aplicación real, los procesos de suburbanización se aceleran, los impactos negativos sobre las áreas periurbanas son cada vez más visibles y se incrementa la fragmentación del territorio con la consiguiente pérdida de biodiversidad.

En este sentido, múltiples estudios (Yokohari et al., 2000; Yang y Jinxing, 2007; Brown et al., 2004), relacionan la consecución de la sostenibilidad en estas áreas con el modelo de anillos verdes, ya que sirven para limitar el crecimiento de la ciudad, conservar áreas naturales y espacios verdes próximos a la ciudad o preservar áreas de cultivo y bosques. Pueden, asimismo, contribuir a dotar a la ciudad de un espacio para actividades de ocio (Bengston y Youn, 2006) y cumplen una clara función ecológica puesto que reducen la contaminación atmosférica, sirven para controlar el riesgo de inundaciones o permiten conservar la biodiversidad (Kahn y Abbasi, 2000; Mortberg y Wallentinus, 2000).

Los orígenes de estas prácticas, que están siendo acometidas en numerosos países a lo largo y ancho del planeta (Ontario, Copenague, Tokyo, Seúl, Moscú, etc.), se pueden encontrar en las propuestas realizadas por Ebenezer Howard a finales del siglo XIX. Howard (1898), partiendo de algunas ideas del reformismo utópico, consideraba que las ciudades de la época estaban sobredimensionadas y las condiciones de vida era pésimas, sobre todo, para las clases obreras. Para superar estos problemas, proponía que la descongestión de las gran- 
des ciudades se hiciese mediante ciudades jardín, células urbano-rurales rodeadas de anillos verdes que permitirían, combinar los beneficios tanto de las áreas rurales como urbanas y evitar los aspectos negativos de ambas. Estos anillos también servirían para controlar el crecimiento de la ciudad, imponiendo unos límites físicos a la ciudad.

Con fines diferentes a los del control del crecimiento de la ciudad, pero en cierta medida, estableciendo los límites de la misma, el Ayuntamiento de Vitoria-Gasteiz lleva muchos años trabajando en la configuración de su Anillo Verde. Este proyecto emblemático que ha sido seleccionado por la ONU entre los cien mejores prácticas en el III Concurso Internacional de Buenas Prácticas, le ha llevado, junto a otras actuaciones en pro de la sostenibilidad implementadas en la ciudad, a obtener el galardón Green Capital 2012.

La idea de crear un anillo verde alrededor de la ciudad de Vitoria-Gasteiz fue concebida en la segunda mitad de los años ochenta, tras numerosos años de prácticas inapropiadas y de alarmante degradación de las zonas periféricas de la ciudad. El proyecto fue pensado como un conjunto de parques periurbanos que incluyesen los humedales de Salburua, las campas de Olarizu, el Bosque de Armentia, el Parque de Zabalgana, el corredor del Zadorra, conectados mediante diferentes elementos que actuasen a modo de corredores ecológicos.

Los objetivos perseguidos fueron tanto de carácter medioambiental, como social y económico. Uno de los prioritarios fue la conservación de los espacios naturales periurbanos y su integración en la estructura urbana, permitiendo la recuperación de la biodiversidad de la zona. Pero, también se incidió mucho en los aspectos sociales del proyecto buscando satisfacer las necesidades de espacios de esparcimiento y contacto con la naturaleza de los vitorianos. Además, estos espacios se presentan como lugares óptimos para llevar a cabo programas de educación y concienciación ambiental. Por último, aspectos económicos como el de la revalorización de los terrenos próximos al anillo verde o de la promoción turística también han sido considerados.

Entre las actuaciones acometidas, es muy destacable la labor realizada en la recuperación y puesta en valor de los humedales de Salburua. Gracias a los trabajos iniciados en el año 1994 se han recuperado las balsas existentes en la zona y en la actualidad, este enclave presenta un gran valor ecológico ya que da cobijo a numerosas especies de aves acuáticas y a otras especies amenazadas como el visón europeo. Por ello, fue declarado zona de importancia internacional por el Convenio Ramsar en el año 2002. Además, el Ayuntamiento ha firmado un convenio con Basquetour (la Agencia Vasca de Promoción Turística) para que este parque forme parte de una red de turismo ornitológico dentro del marco del proyecto «Birding Euskadi», a través del cual se pretende convertir el recurso avifaunístico en un producto turístico de ocio y naturaleza.

Otra actuación reseñable ha sido la adecuación hidráulica y la restauración ambiental acometida en el río Zadorra a su paso por la ciudad. Con este proyecto, se pretende paliar las consecuencias de los episodios periódicos de inundaciones que se han dado en la ciudad. Al mismo tiempo, también se persigue articular un corredor ecológico y la conexión de los parques de Salburua y Zabalgana.

Es fundamental también el hecho de que en todas las actuaciones puestas en marcha se han tenido como principios ordenadores la reforestación y recuperación de la vegetación en las zona mediante especies autóctonas, su acondicionamiento para uso público, realizando los itinerarios y accesos necesarios y dotando de instalaciones a los parques, así como la bús- 
queda de conectividad entre los distintos espacios para conseguir crear corredores ecológicos que permitan el tránsito de la fauna.

Otro aspecto destacable es la búsqueda de la ecoeficiencia y el fácil mantenimiento de las dotaciones e infraestructuras existentes en los diferentes parques que componen el anillo. En este sentido, los parques carecen de luz artificial, el mobiliario utilizado está realizado con materiales naturales de fácil mantenimiento, la repoblación de las diferentes zonas se ha realizado con plantas autóctonas que requieren pocos cuidados y los diversos servicios como aparcamientos, contenedores de basuras, puntos de información y fuentes están localizados únicamente en las entradas a los parques.

Los resultados obtenidos después de casi dos décadas de trabajo muestran no sólo la viabilidad técnica y económica del proyecto sino también los beneficios sociales, ya que un número creciente de habitantes participan en las actividades desarrolladas y el uso por la ciudadanía es cada vez mayor, tratando de inculcar un uso de estas áreas respetuoso con el medio ambiente. También, se puede subrayar el acierto de intentar reducir al mínimo el coste de mantenimiento de los parques mediante la introducción de vegetación nativa y escasos equipamientos. Esto permite asegurar su viabilidad económica y que, además en épocas de contención del gasto público como en la que nos encontramos, el proyecto no sea percibido sólo como un despilfarro. La búsqueda y el logro de fuentes de financiación adicionales como pueden ser los fondos europeos, la financiación estatal o autonómica y las aportaciones de entidades privadas locales pueden ser también muy importantes para la continuidad y ampliación del proyecto.

Sin embargo, al no contar con una legislación específica al margen del Plan General de Ordenación Urbana, el proceso se está desarrollando de una manera poco planificada y coherente debido a las disparidades que se dan en los ritmos de los procesos de planificación y administrativos. Asimismo, se puede considerar una debilidad del proyecto el hecho de que las actuaciones propuestas no son vinculantes legalmente sino que simplemente son objetivos deseables.

Además, otros de los problemas a los que estas áreas periurbanas deben hacer frente, y que están mucho más extendidos que en las zonas rurales, son los causados por la acción humana (la contaminación del aire y agua, las perturbaciones causadas por el tráfico motorizado y las molestias causadas por los visitantes). En Vitoria-Gasteiz, los usos más problemáticos son, sobre todo, los relacionados con el tráfico de vehículos a motor, con el vandalismo y con la excesiva frecuencia de visitantes y usos recreativos intensivos de algunos espacios.

De cara al futuro, la conservación de estos enclaves pasa por mejorar la conectividad entre los distintos parques y la conexión del Anillo Verde con los Montes de Vitoria. De hecho, uno de los proyectos emblemáticos en los que la Diputación Foral de Álava está trabajando en este momento es la construcción de un segundo cinturón verde exterior que incluya nuevos espacios naturales alejados de la ciudad con la consiguiente ampliación a un territorio mucho más amplio que incluya también a numerosos núcleos rurales de la provincia.

Igualmente, es necesaria la mejora de la accesibilidad y la creación de sendas urbanas y carriles bici que conecten los barrios con los parques del Anillo Verde. Estos parques pueden servir para satisfacer la necesidad de áreas verdes en los barrios nuevos de la ciudad y quizá compensar la falta de este tipo de dotaciones dentro de la ciudad, teniendo en cuenta que los 
parques urbanos, generalmente, tienen un alto coste de mantenimiento (siembra, riego, poda, corte de césped, etc.) y con frecuencia están infrautilizados.

Por último, no debemos rechazar la idea de que el Anillo Verde de Vitoria-Gasteiz puede servir para prevenir el crecimiento descontrolado mediante la imposición de una frontera de expansión de la ciudad. En este punto, las prácticas para fomentar la redensificación de los barrios nuevos se pueden considerar apropiadas. 